\title{
ANALISIS KEKUATAN PEGAS DAUN KIJANG SERI 5k SEBELUM DAN SESUDAH MODIFIKASI PENEKANAN
}

\author{
Margono Sugeng', Rizki Adi Kurniawan² \\ Program Studi Teknik Mesin, Institut Sains dan Teknologi Nasional, Jakarta ${ }^{1} 2$ \\ email ${ }^{1}$ : margono.s@istn.ac.id
}

\begin{abstract}
Leaf spring is one of the components contained in the rear suspension system and made from high carbon carbon steel. Nowadays, many people do leaf spring modifications, one of them is by the pressing process, but many of the vehicle owners modify it excessively and finally leaf springs broken. Therefore to know how the strength of leaf springs is done by testing the chemical composition test, metallographic test, hardness test and tensile test, the test is done in PT.IWWI located in tangerang area. The sample used to perform the test consisted of 4 samples, namely sample $A$, sample $B$, sample $C$ and sample $D$, taken from each spring number 3 which has been modified as much as $2 \mathrm{~cm}$ and that has not been modified. From the four tests obtained results from testing the chemical composition of carbon content contained in sample $C$ is highest with the value of carbon content contained 0.7719. From the hardness testing of sample which has the highest hardness value is sample $C$ with hardness value 111.06 [kgf]. and from the sample tensile strength test which has the highest tensile strength value is sample $B$ with a tensile strength value of 1408.75 [N/ mm2].
\end{abstract}

Keywords: Leaf spring, pressing modification, testing

\section{PENDAHULUAN}

Pegas daun merupakan salah satu komponen yang terdapat pada sistem suspensi belakang dan berbahan karbon baja karbon tinggi. Dalam fungsinya pegas daun menerima beban dinamis (yang berulang-ulang) yang cukup besar dan akan mengalami kerusakan akibat lelah yang muncul setelah komponen tersebut menjalani fungsinya. Sekarang ini, banyak orang melakukan modifikasi pegas daun, salah satunya adalah dengan melakukan proses penekanan (pressing) sehingga penampang pegas daun menjadi rata. Penekanan ini dapat mengurangi fungsi pegas daun, baik sebagai komponen sistem suspensi maupun sebagai penompang kendaraan. Akibatnya terjadi fase plastisitas yaitu terjadinya vibrasi yang tinggi serta elastistas pegas berkurang sehingga mengurangi kenyamanan dan keamanaan pengendara. Seberapa besar perubahan kekuatan dan kekerasan pada pegas daun yang di modifikasi dengan penekanan sehingga penampangnya menjadi rata sangat menarik untuk di teliti. Untuk itu pada penelitian ini dilakukan studi perubahan kekuatan dan kekerasan pada pegas daun tersebut dengan menganalisis pengaruh yang ditimbulkan sebelum dan sesudah dilakukan pressing serta gaya-gaya yang terjadi dan dampaknya terhadap elastisitas pegas secara eksperimental. Dengan dilakukannya proses penekanan maka pegas daun akan berubah kekuatannya dan pegas daun akan mudah patah yang bisa mengakibatkan kecelakaan yang diakibatkan dari proses modifikasi pegas tersebut. Karena akhir-akhir ini banyak pemilik kendaraan yang mengalami hal tersebut. Banyak pemilik kendaraan mengalami pegas daun patah saat setelah pegas daun dilakukan modifikasi penekanan untuk menguranginya kita harus mengetahui seberapa kuat batas maksimal pegas daun dilakukan proses modifikasi penekanan jika pemilik kendaraan tidak ingin mengganti pegas daun lamanya.

\section{TINJAUAN PUSTAKA}

\section{Tinjauan Terhadap Pegas Daun}

Pegas adalah benda elastis yang digunakan untuk menyimpan energi mekanis. Pegas biasanya terbuat dari baja. Pegas juga ditemukan di sistem suspensi mobil. Pada mobil, pegas memiliki fungsi menyerap kejut dari jalan dan getaran roda agar tidak diteruskan ke bodi kendaraan secara langsung. Selain itu, pegas juga berguna untuk menambah daya cengkeram ban terhadap permukaan jalan. 


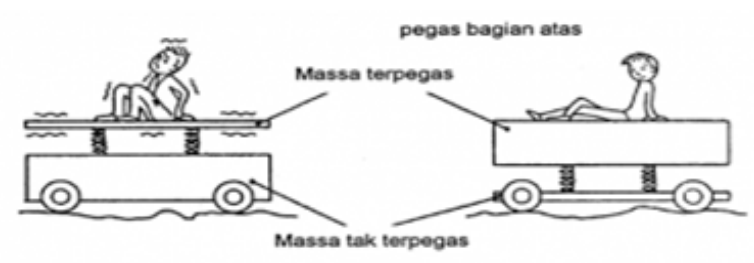

Gambar 1 posisi pegas

Sumber. Winof otomotif, "pegas dan macammacam pegas”, winof.wordpress.com. diakses 20 oktober 2017

\section{Uji Komposisi Kimia}

Pengujian ini dilakukan untuk mengetahui unsur-unsur kimia yang terkandung dalam material yang akan diuji. Dengan mengetahui unsur-unsur yang terkandung dalam material tersebut maka kita dapat melihat panduan yang tercampur di dalam material yang akan diuji dan dapat mengambil kesimpulan dari data-data tersebut. Adapun langkah kerja dari pengujian komposisi kimia adalah seperti terlihat dibawah ini:

Sebelum dilakukan pengujian material terlebih dahulu dilakukan pengamplasan sampai didapat permukaan yang rata dan selanjutnya material diletakkan pada tempat material uji untuk dilakukan pembakaran oleh elektroda. Pantulan dari cahaya pembakaran akan dipantulkan dan disebarkan oleh spektrometer menuju spektra sesuai dengan unsur yang terkandung oleh material uji. Selanjutnya spektra akan menganalisa dan menyeleksi kemudian diteruskan kepada photomultiplier detector. Hasil pengujian akan keluar dari photomultiplier detector yang kemudian diteruskan oleh spectral intensity dan selanjutnya dilakukan perhitungan oleh masing-masing integrator untuk setiap unsurnya. Pembakaran akan mati setelah perhitungan dari unsur pada material selesai dengan hasil pengukuran dalam bentuk signal elektrik. Signal tersebut akan dikonversikan dalam bentuk persentase unsur untuk ditampilkan oleh monitor komputer untuk selanjutnya dicetak.

\section{Uji Metalografi}

Metalografi merupakan disiplin ilmu yang mempelajari karakteristik mikrostruktur dan makrostruktur suatu logam, paduan logam dan material lainnya serta hubungannya dengan sifatsifat material, atau biasa juga dikatakan suatu proses untuk mengukur suatu material baik secara kualitatif maupun kuantitatif berdasarkan informasi-informasi yang didapatkan dari material yang diamati. Dalam ilmu metalurgi struktur mikro merupakan hal yang sangat penting untuk dipelajari. Karena struktur mikro sangat berpengaruh pada sifat fisik dan mekanik suatu logam. Struktur mikro yang berbeda sifat logam akan berbeda pula. Struktur mikro yang kecil akan membuat kekerasan logam akan meningkat. Dan juga sebaliknya, struktur mikro yang besar akan membuat logam menjadi ulet atau kekerasannya menurun. Struktur mikro itu sendiri dipengaruhi oleh komposisi kimia dari logam atau paduan logam tersebut serta proses yang dialaminya. Metalografi bertujuan untuk mendapatkan struktur makro dan mikro suatu logam sehingga dapat dianalisa sifat mekanik dari logam tersebut.

\section{Uji Kekerasan}

Uji kekerasan adalah pengujian yang paling efektif untuk menguji kekerasan dari suatu material, karena dengan pengujian ini kita dapat dengan mudah mengetahui gambaran sifat mekanis suatu material. Meskipun pengukuran hanya dilakukan pada suatu titik, atau daerah tertentu saja, nilai kekerasan cukup valid untuk menyatakan kekuatan suatu material. Dengan melakukan uji keras, material dapat dengan mudah di golongkan sebagai material ulet atau getas.

Mengapa diperlukan pengujian kekerasan? Di dalam aplikasi manufaktur, material dilakukan pengujian dengan dua pertimbangan yaitu untuk mengetahui karakteristik suatu material baru dan melihat mutu untuk memastikan suatu material memiliki spesifikasi kualitas tertentu.

Tabel 1 Rockwell Hardness Scale

\begin{tabular}{|c|c|c|c|c|c|c|}
\hline scale & Indentor & $\begin{array}{l}\text { Fo } \\
\text { kgf }\end{array}$ & $\begin{array}{l}\text { F1 } \\
\text { (kgf }\end{array}$ & $\begin{array}{l}\mathbf{F} \\
(\mathrm{kgf})\end{array}$ & $E$ & \begin{tabular}{|l}
$\begin{array}{l}\text { Jenis Material } \\
\text { Uji }\end{array}$ \\
\end{tabular} \\
\hline $\mathbf{A}$ & \begin{tabular}{|l|} 
Diamond \\
cone
\end{tabular} & 10 & 50 & 60 & & $\begin{array}{l}\text { Exremely hard } \\
\text { materials, } \\
\text { tugsen carbides, } \\
\text { dll }\end{array}$ \\
\hline 3 & $\begin{array}{l}1 / 16^{\prime \prime} \\
\text { steel ball }\end{array}$ & 10 & 90 & 100 & & $\begin{array}{l}\text { Medium hard } \\
\text { materials, low } \\
\text { dan medium } \\
\text { carbon steels, } \\
\text { kuningan, } \\
\text { perunggu, dll }\end{array}$ \\
\hline $\bar{C}$ & $\begin{array}{l}\text { Diamond } \\
\text { cone }\end{array}$ & 10 & 140 & 150 & & $\begin{array}{l}\text { ed steels, } \\
\text { ed and } \\
\text { ed alloys }\end{array}$ \\
\hline 5 & $\begin{array}{l}\text { Diamond } \\
\text { cone }\end{array}$ & 10 & 90 & 100 & & an dan \\
\hline $\bar{E}$ & $\begin{array}{l}\text { 1/8" steel } \\
\text { ball }\end{array}$ & 10 & 90 & 100 & & $\begin{array}{l}\text { Berrylium } \\
\text { copper,phosphor } \\
\text { bronze, dll }\end{array}$ \\
\hline $\mathbf{F}$ & $\begin{array}{l}1 / 16^{\prime \prime} \\
\text { steel ball }\end{array}$ & 10 & 50 & 60 & & $\begin{array}{l}0 \text { Alumunium } \\
\text { sheet }\end{array}$ \\
\hline $\bar{G}$ & $\begin{array}{l}1 / 16^{\prime \prime} \\
\text { steel ball }\end{array}$ & 10 & 140 & 150 & & $\begin{array}{l}0 \text { Cast iron, } \\
\text { alumunium } \\
\text { alloys }\end{array}$ \\
\hline $\mathbf{H}$ & $\begin{array}{l}1 / 8 " \text { steel } \\
\text { ball }\end{array}$ & 10 & 50 & 60 & & $\begin{array}{l}\text { Plastik dan soft } \\
\text { metals seperti } \\
\text { timah }\end{array}$ \\
\hline
\end{tabular}




\begin{tabular}{|c|c|c|c|c|}
\hline K & \begin{tabular}{|l|l|}
$1 / 8 "$ steel 10 \\
ball
\end{tabular} & 140 & 150 & \begin{tabular}{|l|l|}
130 & $\begin{array}{l}\text { Sama dengan } \mathrm{H} \\
\text { scale }\end{array}$ \\
\end{tabular} \\
\hline $\mathbf{L}$ & $\begin{array}{l}1 / 4 " \text { steel } 10 \\
\text { ball }\end{array}$ & 50 & 60 & $130 \begin{array}{l}\text { Sama dengan } \mathrm{H} \\
\text { scale }\end{array}$ \\
\hline $\mathbf{M}$ & \begin{tabular}{|l|l|}
$1 / 4 "$ steel 10 \\
ball
\end{tabular} & 90 & 100 & $130 \begin{array}{l}\text { Sama dengan } \mathrm{H} \\
\text { scale }\end{array}$ \\
\hline$\overline{\mathbf{P}}$ & \begin{tabular}{|l|l|}
$1 / 4 "$ steel 10 \\
ball
\end{tabular} & 140 & 150 & $130 \begin{array}{l}\text { Sama dengan } \mathrm{H} \\
\text { scale }\end{array}$ \\
\hline $\mathbf{R}$ & $\begin{array}{l}1 / 2 " \text { steel } 10 \\
\text { ball }\end{array}$ & 50 & 60 & $130 \mid \begin{array}{l}\text { Sama dengan } \mathrm{H} \\
\text { scale }\end{array}$ \\
\hline$S$ & \begin{tabular}{|l|l|}
$1 / 2 "$ steel 10 \\
ball
\end{tabular} & 90 & 100 & $130 \begin{array}{l}\text { Sama dengan } \mathrm{H} \\
\text { scale }\end{array}$ \\
\hline V & $\begin{array}{l}1 / 2 " \text { steel } 10 \\
\text { ball }\end{array}$ & 140 & 150 & $130 \begin{array}{l}\text { Sama dengan } \mathrm{H} \\
\text { scale }\end{array}$ \\
\hline
\end{tabular}

\section{Uji Tarik}

Uji Tarik merupakan salah satu pengujian untuk mengetahui sifat-sifat suatu bahan. Dengan menarik suatu bahan kita akan segera mengetahui bagaimana bahan tersebut bereaksi terhadap tenaga tarikan dan mengetahui sejauh mana material itu bertambah panjang. Alat eksperimen untuk uji tarik ini harus memiliki cengkeraman (grip) yang kuat dan kekakuan yang tinggi (highly stiff). Banyak hal yang dapat kita pelajari dari hasil uji tarik. Bila kita terus menarik suatu bahan (dalam hal ini suatu logam) sampai putus, kita akan mendapatkan profil tarikan yang lengkap yang berupa kurva seperti digambarkan pada Gambar 2. Kurva ini menunjukkan hubungan antara gaya tarikan dengan perubahan panjang. Profil ini sangat diperlukan dalam desain yang memakai bahan tersebut.

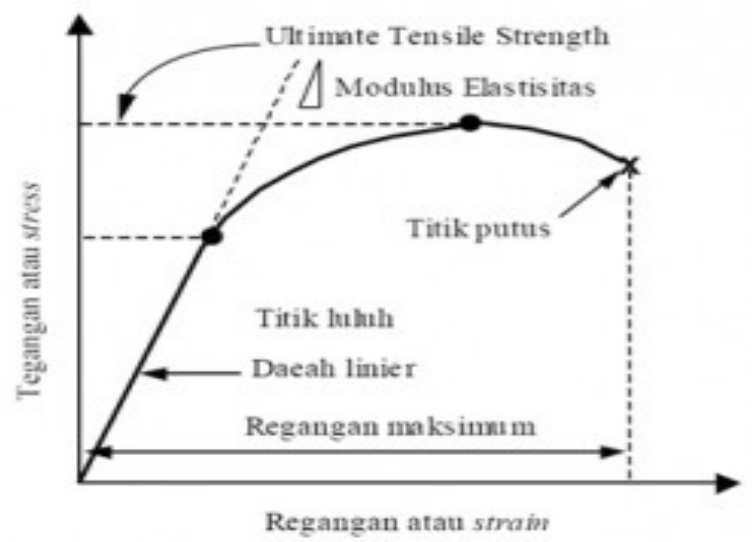

Gambar 2 Diagram UTS

Sumber Bhakti, Dadang MH (2013). ”Diktat Kuliah

Teknologi Bahan”. Politeknik Negeri Jakarta, halaman 23

Hukum Hooke (Hooke's Law) Hampir semua logam, pada tahap sangat awal dari uji tarik, hubungan antara beban atau gaya yang diberikan berbanding lurus dengan perubahan panjang bahan tersebut. Ini disebut daerah linier atau linear zone. Di daerah ini, kurva pertambahan panjang vs beban mengikuti aturan Hooke yaitu rasio tegangan (stress) dan regangan (strain) adalah konstan. "Stress adalah beban dibagi luas penampang bahan" "strain adalah pertambahan panjang dibagi panjang awal bahan" Dirumuskan, Stress (Tegangan Mekanis):

$$
\sigma=\mathrm{F} / \mathrm{A}
$$

$\mathrm{F}$ = gaya tarikan

$\mathrm{A}=$ luas penampang

Strain (Regangan):

$$
\varepsilon=\Delta \mathrm{L} / \mathrm{L}
$$

$\Delta \mathrm{L}=$ Pertambahan panjang

$\mathrm{L} \quad=$ Panjang awal

Maka, hubungan antara stress dan strain dirumuskan:

$\mathrm{E}=$ Elongation

$$
\mathrm{E}=\sigma / \varepsilon
$$

$\sigma=$ Tegangan

$\varepsilon=$ Regangan

\section{METODE DAN PENGOLAHAN DATA \\ Metode penelitian}

Berdasarkan Gambar 3 dijelaskan metode penelitian sebagai dasar untuk menyelesaikan penelitian. Tahapannya yaitu mengumpulkan data, mengolah data tersebut, lalu melakukan analisis. Produk akhir dari analisis dapat dimunculkan rekomendasi untuk improvement sistem.

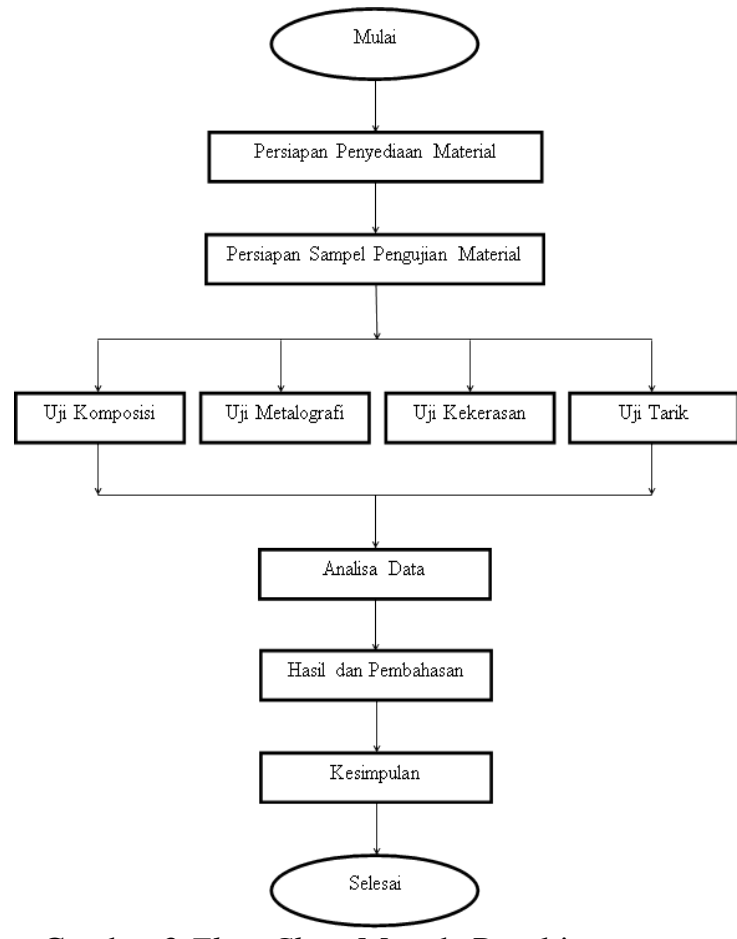

Gambar 3 Flow Chart Metode Peneltian 


\section{Prosedur Pengambilan Data}

Spesifikasi benda uji yang digunakan dalam eksperimen ini adalah sebagai berikut
a. Jenis bahan yang digunakan adalah AISI 1095 baja paduan tinggi.
b. Ketebalan plat 7 [mm].
c. Bentuk spesimen untuk mengacu standart AWS D1.1.
d. Bentuk spesimen benda uji standar JIS G4801 untuk pengujian komposisi kimia.
e. Bentuk spesimen benda uji standar JIS G4801 untuk pengujian metalografi.
f. Bentuk spesimen benda uji standar ASTM E384 untuk pengujian kekerasan.
g. Bentuk spesimen benda uji standar ASTM E-8 untuk pengujian tarik.

\section{Spesifikasi Data}

Berikut adalah tabel data pengujian kekerasan terhadap material yang telah disiapkan, dan pengujian ini dilakukan dengan 6 titik lokasi pengujian pada masing-masing sample dengan metode rockwell:

Tabel 2 Pengujian Kekerasan Sample A

\begin{tabular}{|c|c|c|}
\hline Sample A & Hardness Value & Scale \\
\hline Titik 1 & 106.13 & HRB \\
\hline Titik 2 & 106.35 & HRB \\
\hline Titik 3 & 109.23 & HRB \\
\hline Titik 4 & 111.06 & HRB \\
\hline Titik 5 & 105.99 & HRB \\
\hline Titik 6 & 106.46 & HRB \\
\hline Ave. & 107.53 & HRB \\
\hline
\end{tabular}

Tabel 3 Pengujian Kekerasan Sample B

\begin{tabular}{|c|c|c|}
\hline Sample B & Hardness Value & Scale \\
\hline Titik 1 & 104.63 & HRB \\
\hline Titik 2 & 111.55 & HRB \\
\hline Titik 3 & 102.18 & HRB \\
\hline Titik 4 & 115.66 & HRB \\
\hline Titik 5 & 110.34 & HRB \\
\hline Titik 6 & 107.35 & HRB \\
\hline Ave. & 108.61 & HRB \\
\hline
\end{tabular}

Tabel 4 Pengujian Kekerasan Sample C

\begin{tabular}{|c|c|c|}
\hline Sample C & Hardness Value & Scale \\
\hline Titik 1 & 113.79 & HRB \\
\hline Titik 2 & 111.44 & HRB \\
\hline Titik 3 & 111.20 & HRB \\
\hline Titik 4 & 110.16 & HRB \\
\hline Titik 5 & 109.39 & HRB \\
\hline Titik 6 & 110.41 & HRB \\
\hline Ave. & 111.06 & HRB \\
\hline
\end{tabular}

Tabel 5 Pengujian Kekerasan Sample D

\begin{tabular}{|c|c|c|}
\hline Sample D & Hardness Value & Scale \\
\hline Titik 1 & 108.89 & HRB \\
\hline Titik 2 & 108.10 & HRB \\
\hline Titik 3 & 109.99 & HRB \\
\hline Titik 4 & 106.15 & HRB \\
\hline Titik 5 & 110.71 & HRB \\
\hline Titik 6 & 108.80 & HRB \\
\hline Ave. & 108.77 & HRB \\
\hline
\end{tabular}

Berikut adalah tabel data pengujian uji tarik terhadap material yang telah disiapkan, dan pengujian ini dilakukan dengan 4 sample.

Tabel 6 Data Pengujian Uji Tarik

\begin{tabular}{|c|c|c|c|c|}
\hline Sample & $\begin{array}{c}\sum \mathrm{u} \\
{\left[\mathrm{N} / \mathrm{mm}^{2}\right]}\end{array}$ & $\begin{array}{c}\Delta \mathrm{A} \\
{\left[\mathrm{mm}^{2}\right]}\end{array}$ & $\begin{array}{c}\text { Elongati } \\
\text { on } \\
{[\%]}\end{array}$ & $\begin{array}{c}\text { Re.of } \\
\text { area } \\
{[\%]}\end{array}$ \\
\hline A & 1284.86 & 2.8 & 16 & 27.02 \\
\hline B & 1408.75 & 1.1 & 6 & 10.70 \\
\hline C & 1363.33 & 2.8 & 12 & 32.32 \\
\hline D & 1305.92 & 0.7 & 10 & 24.11 \\
\hline
\end{tabular}

Keterangan : $\Sigma \mathrm{u}=$ Tegangan yang mampu diterima oleh material [N/mm2].

$\Delta \mathrm{A}=$ Pertambahan Luas spesimen setelah diuji $[\mathrm{mm}]$.

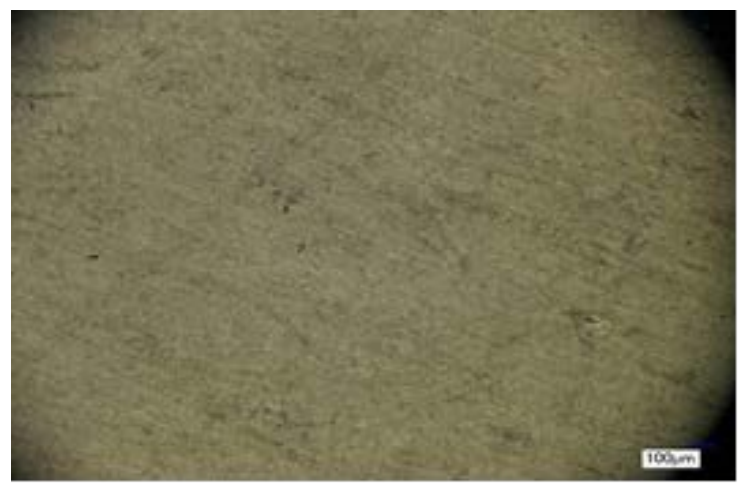

Gambar 4 Microstructure Sample A

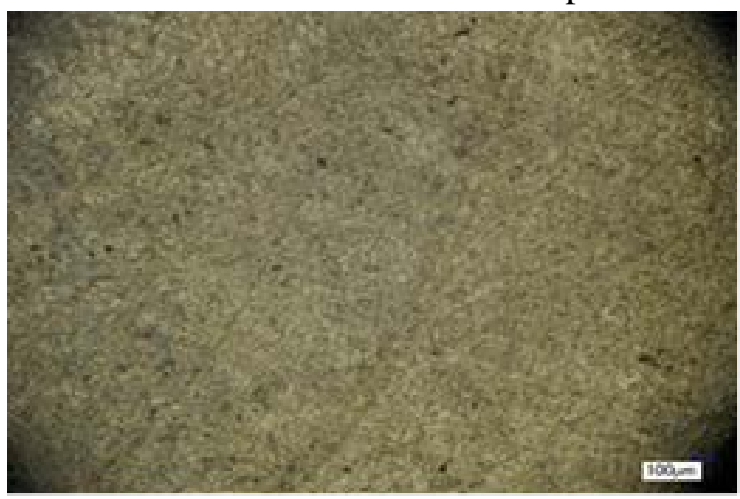

Gambar 5 Microstructure Sample B 


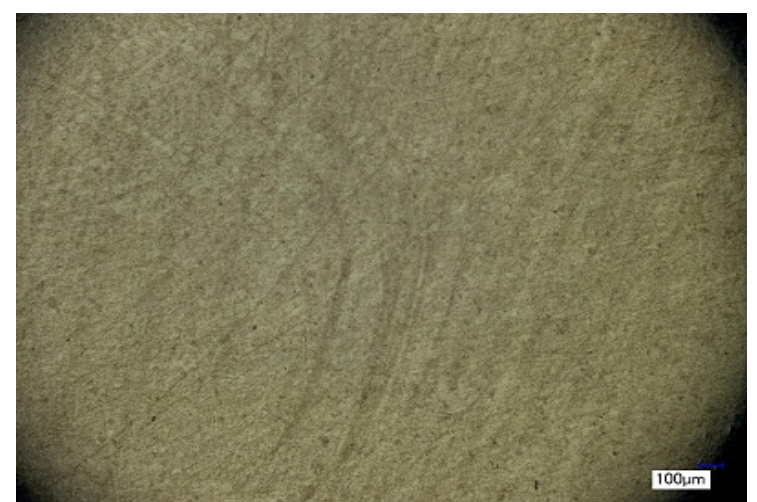

Gambar 6 Microstructure Sample C

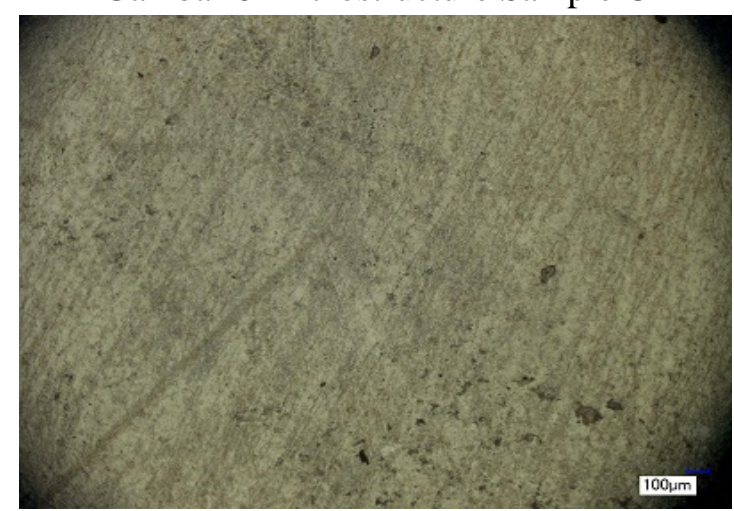

Gambar 7 Microstructure Sample D

Dari hasil pengujian metalografi diatas kita bisa melihat dan membandingkan microstructure yang ada :

Sample A dapat kita lihat dengan pembesaran 100 kali permukaan terlihat serat serat yang ada belum terlalu banyak terkontaminasi dengan bercak-bercak hitam hanya sedikit saja bercak yang ada, dan ini menandakan bahwa material belum terlalu banyak mengalami perubahan zat kimia. Sample B dapat kita lihat dengan pembesaran 100 kali permukaan terlihat lebih kotor dari Sample A dan banyak sekali bercak-bercak hitam yang ada, dan ini menandakan bahwa material telah mengalami banyak perubahan proses zat kimia dan material telah terkontaminasi. Sample C dapat kita lihat dengan pembesaran 100 kali permukaan terlihat sangat bersih tidak terlihat adanya bercakbercak hitam yang terlihat hanya serat serat dari material tersebut, dan ini menandakan bahwa material belum sama sekali mengalami perubahan zat kimia dan belum terkontaminasi. Sample D dapat kita lihat dengan pembesaran 100 kali permukaan terlihat bercak-bercak hitam berukuran besar yang akan berubah menjadi sifat-sifat korosif ini menandakan material telah mengalami perubahan zat kimia. Setelah dilakukan proses penekanan pada sample $\mathrm{C}$ dengan kondisi baru terlihat lebih banyak garis-garis halus yang memungkinkan bisa menyebabkan material mudah patah, bandingkan dengan sample A terlihat tidak terlalu banyak garisgaris halusnya. Setelah dilakukan proses penekanan pada sample D dengan kondisi berusia 10 tahun terlihat banyak sekali garis-garis yang melintang dan menitik pusat hal ini bisa menyebabkan material akan mudah sekali patah karena garis-garis tersebut dikelilingi dengan bercak-bercak hitam yang menandakan material sudah mengalami proses korosi, bandingankan dengan sample $\mathrm{B}$ terlihat garis-garis halus tidak terlalu kelihatan dan memungkin lifetime akan lebih lama dibandingkan dengan sample D.

Tabel 7 Data Komposisi Kimia Sample A

\begin{tabular}{|c|c|c|c|c|}
\hline $\begin{array}{c}\text { Sample } \\
\mathrm{A}\end{array}$ & INT & $\mathrm{C}$ & $\mathrm{Cr}$ & $\mathrm{Al}$ \\
\hline $\mathrm{N}=1$ & 3.7218 & 0.5206 & 0.6920 & 0.0293 \\
\hline $\mathrm{N}=2$ & 3.6877 & 0.5675 & 0.7006 & 0.0296 \\
\hline Ave. & 3.7048 & 0.5440 & 0.6963 & 0.0294 \\
\hline
\end{tabular} $\begin{aligned} & \text { Dari data diatas diketahui bahwa carbon yang } \\
& \text { terkandung adalah } 0.5440 \text { maka diestimasi AISI } \\
& 1055\end{aligned}$

Tabel 8 Data Komposisi Kimia Sample B

\begin{tabular}{|c|c|c|c|c|}
\hline $\begin{array}{c}\text { Sample } \\
\mathrm{B}\end{array}$ & $\mathrm{INT}$ & $\mathrm{C}$ & $\mathrm{Cr}$ & $\mathrm{Al}$ \\
\hline $\mathrm{N}=1$ & 3.6780 & 0.6817 & 0.7812 & 0.0228 \\
\hline $\mathrm{N}=2$ & 3.6559 & 0.6951 & 0.7752 & 0.0229 \\
\hline Ave. & 3.6669 & 0.6884 & 0.7782 & 0.0228 \\
\hline
\end{tabular}

Dari data diatas diketahui bahwa carbon yang terkandung adalah 0.6884 maka diestimasi AISI 1070

Tabel 9 Data Komposisi Kimia Sample C

\begin{tabular}{|c|c|c|c|c|}
\hline $\begin{array}{c}\text { Sample } \\
\mathrm{C}\end{array}$ & INT & $\mathrm{C}$ & $\mathrm{Cr}$ & $\mathrm{Al}$ \\
\hline $\mathrm{N}=1$ & 3.7303 & 0.7599 & 0.6446 & 0.0071 \\
\hline $\mathrm{N}=2$ & 3.5890 & 0.7839 & 0.6486 & 0.0072 \\
\hline Ave. & 3.6599 & 0.7719 & 0.6466 & 0.0071 \\
\hline
\end{tabular}

Dari data diatas diketahui bahwa carbon yang terkandung adalah 0.7719 maka diestimasi AISI 1080

Tabel 10 Data Komposisi Kimia Sample D

\begin{tabular}{|c|c|c|c|c|}
\hline $\begin{array}{c}\text { Sample } \\
\mathrm{D}\end{array}$ & INT & $\mathrm{C}$ & $\mathrm{Cr}$ & $\mathrm{Al}$ \\
\hline $\mathrm{N}=1$ & 3.4693 & 0.7051 & 0.6794 & 0.0249 \\
\hline $\mathrm{N}=2$ & 3.6061 & 0.6794 & 0.6773 & 0.0253 \\
\hline Ave. & 3.5377 & 0.6922 & 0.6784 & 0.0251 \\
\hline
\end{tabular}

Dari data diatas diketahui bahwa carbon yang terkandung adalah 0.6922 maka di estimasi AISI 1070

\section{ANALISIS DATA \\ Analisa Uji Komposisi Kimia}

Dari data pengujian komposisi kimia didapat hasil kandungan karbon pada sample A 
adalah 0.5440, pada sample B adalah 0.6884, pada sample C adalah 0.7719 dan pada sample D adalah 0.6922, oleh karena itu komposisi karbon yang paling besar adalah sample $C$ yaitu sample dengan kondisi baru dan telah dilakukan modifikasi.

\section{Analisa Uji Metalografi}

Dari data pengujian metalografi didapat hasil microstructure pada masing-masing sample dengan pembesaran 100 kali pada sample A terlihat ada sedikit bercak hitam dan sedikit garis halus, pada sample B terlihat banyak bercakbercak hitam dan sedikit garis halus, pada sample $\mathrm{C}$ terlihat tidak adanya bercak hitam tetapi garisgaris halus terlihat sangat jelas, pada sample D terlihat banyak bercak-bercak hitam dan garisgaris halus terlihat sangat jelas, oleh karena itu hasil microstructure yang paling bagus adalah sample C.

\section{Analisis Uji Kekerasan}

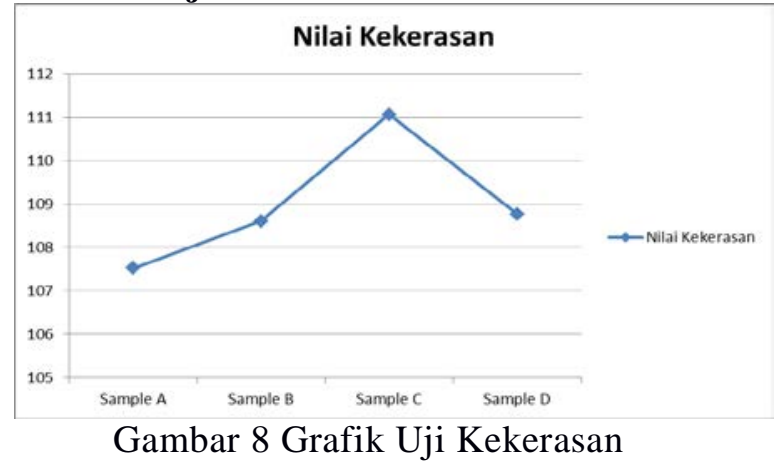

Dari grafik diatas bisa dilihat bahwa nilai kekerasan yang paling tinggi pada sample A berada pada titik 4, dan nilai kekerasan paling rendah berada pada titik 5 . Nilai kekerasan ratarata sample A adalah sebesar 107,53 [kgf]. Dari grafik diatas bisa dilihat bahwa nilai kekerasan yang paling tinggi pada sample B berada pada titik 4, dan nilai kekerasan paling rendah berada pada titik 3. Nilai kekerasan rata-rata sample B adalah sebesar 108,61 [kgf]. Dari grafik diatas bisa dilihat bahwa nilai kekerasan yang paling tinggi pada sample $\mathrm{C}$ berada pada titik 1 , dan nilai kekerasan paling rendah berada pada titik 5. Nilai kekerasan rata-rata sample $\mathrm{C}$ adalah sebesar 111,06 [kgf]. Dari grafik diatas bisa dilihat bahwa nilai kekerasan yang paling tinggi pada sample D berada pada titik 5, dan nilai kekerasan paling rendah berada pada titik 4 . Nilai kekerasan ratarata sample D adalah sebesar 108,77 [kgf].

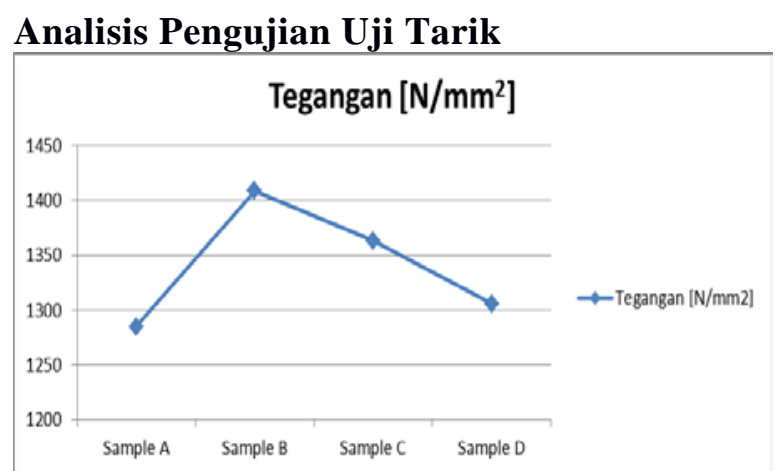

Gambar 9 Grafik Tegangan Uji Tarik

Dari grafik diatas bisa dilihat bahwa sample yang mampu menerima tegangan paling besar adalah sample B dengan nilai tegangan 1408,75 $\mathrm{N} / \mathrm{mm}^{2}$ dan sample yang menerima tegangan paling rendah adalah sample $A$ dengan nilai tegangan $1284,86 \mathrm{~N} / \mathrm{mm}^{2}$.

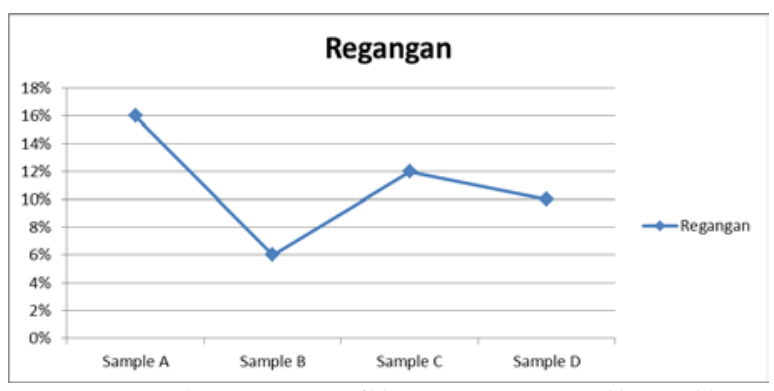

Gambar 10 Grafik Regangan Uji Tarik

Dari grafik diatas bisa dilihat bahwa sample yang memiliki nilai regangan yang paling tinggi adalah sample A dengan nilai regangan 16\%, dan sample yang memiliki nilai regangan terendah adalah sample B dengan nilai regangan 6\%.

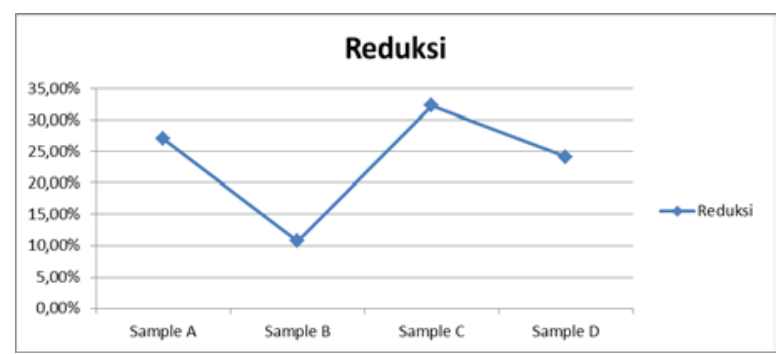

Gambar 11 Grafik Reduksi Uji Tarik

Dari grafik diatas bisa dilihat bahwa sample yang memiliki nilai reduksi paling tinggi adalah sample C dengan nilai reduksi 32,32\% dan sample yang memiliki nilai reduksi terendah adalah sample B dengan nilai reduksi 10,70\%.

\section{KESIMPULAN}

Pengujian yang sudah dilakukan mendapatkan perbedaan data yang dapat dibandingkan dari 4 metode pengujian yaitu uji 
komposisi kimia, uji metalografi, uji kekerasan, dan uji tarik dengan material AISI 1095 dengan spesimen uji berbentuk plat. Pada pengujian keempat metode yang digunakan ini penulis menyimpulkan bahwa :

1. Dari pengujian komposisi kimia kadar karbon yang terkandung pada sample yang paling tinggi adalah sample $\mathrm{C}$ dengan nilai kadar karbon yang terkandung sebesar 0.7719, yaitu baja karbon tinggi paduan chrom.

2. Dari pengujian metalografi didapat hasil microstructure yang paling bagus adalah sample C dimana yang diduga microstructure perlitenya belum bergeser menjadinya karbida.

3. Dari pengujian kekerasan sample yang memiliki nilai kekerasan yang paling tinggi adalah sample $\mathrm{C}$ dengan nilai kekerasan 111.06 [kgf] metode yang digunakan adalah metode rockwell.

4. Dari pengujian kuat tarik sample yang memiliki nilai kuat tarik paling tinggi adalah sample $\mathrm{B}$ dengan nilai kuat tarik sebesar 1408,75 [N/mm²].

5. Dari hasil uji tarik diketahui material yang digunakan adalah material yang bersifat getas untuk mengetahui nilai kegetasannya maka harus dilakukan uji impact.

6. Dari keempat pengujian sample yang hasilnya menunjukan paling bagus adalah sample C karena nilai kekerasannya paling tinggi, microstructure perlitenya belum bergeser menjadi karbida, dan kadar karbon yang terkandung juga lebih besar.

\section{DAFTAR PUSTAKA}

ASM Handbook (2005). "Properties and Selection: Iron Steels and High Performance Alloy”. Volume 1, ASM International, USA

JIS Handbook (2015). "Ferrous Material and Metallurgy". Volume 1, Japanese Standart Association

JIS Handbook (2015). "Ferrous Material and Metallurgy”. Volume 2, Japanese Standart Association

Bhakti, Dadang MH (2013). "Diktat Kuliah Teknologi Bahan”. Politeknik Negeri Jakarta

Daryanto. Drs (2008). “Teknik Merawat Automobil”. Yrama Widya, Bandung

Sofyan, Bondan T (2010). "Pengantar Material Teknik". Jakarta: Salemba Teknika id.wikipedia.org/wiki/sistem_suspensi_(ken daraan) diakses pada tanggal 11 November 2017 winof.wordpress.com/pegas/macam-macam pegas diakses 20 oktober 2017 